\title{
Consórcios de caupi e milho em cultivo orgânico para produção de grãos e espigas verdes
}

\author{
Rejane E Guedes ${ }^{1}$; Norma G Rumjanek²; Gustavo R Xavier²; José Guilherme M Guerra²; Raul de LD \\ Ribeiro ${ }^{3}$ \\ ${ }^{1}$ UFRRJ-Depto. Fitotecnia, Rod. BR 465, km 7, 23890-000 Seropédica-RJ; ${ }^{2}$ Embrapa Agrobiologia, C. Postal 74505, 23851-970 \\ Seropédica-RJ; ${ }^{3}$ UFRRJ, Inst. Agronomia; rejane.guedes@gmail.com; norma@cnpab.embrapa.br; gustavo@cnpab.embrapa.br
}

\begin{abstract}
RESUMO
No período de outono-inverno-primavera de 2007, foi conduzido um estudo em Seropédica, Região Metropolitana do estado do Rio de Janeiro (Baixada Fluminense), com o objetivo de avaliar diferentes tipos de consórcio entre caupi (cv. Mauá) e milho (cv. AG-1051), em sistema orgânico de produção. $\mathrm{O}$ experimento foi instalado em área de Argissolo Vermelho-Amarelo no delineamento de blocos ao acaso, com quatro repetições. Os tratamentos constaram de diferentes épocas ou intervalos de tempo de semeadura do caupi em relação à do milho, a saber: (E1) 21 dias antes do milho; (E2) 14 dias antes do milho; (E3) 7 dias antes do milho; e (E4) no mesmo dia do milho. Tratamentos correspondentes aos cultivos solteiros do caupi e do milho foram incluídos, ambos semeados na data do tratamento E4. O cultivo consorciado com o caupi não interferiu na produtividade do milho em espigas verdes e também em termos de comprimento e diâmetro basal dessas espigas, independentemente do intervalo entre semeaduras. Com referência ao caupi, a produtividade em grãos verdes no cultivo solteiro foi superior à dos consórcios com o milho. Os valores obtidos para os Índices de Equivalência de Área (IEA), foram todos acima de 1,0, indicando que os consórcios foram eficientes quanto ao desempenho agronômico/biológico. Considerando, ainda a produtividade de cada cultura participante do consórcio, a semeadura do caupi antecipada de 21 dias em relação à do milho afigura-se mais adequada ao manejo orgânico adotado e às condições edafoclimáticas da região.
\end{abstract}

Palavras-chave: Vigna unguiculata, Zea mays, Índice de Equivalência de Área, agroecologia.

\section{ABSTRACT}

Cowpea and corn intercrops in organic farming system aiming at production of immature beans and spikes

Covering the period of autumn-winter-spring of 2007, a study was performed in Seropédica, Metropolitan Region of Rio de Janeiro State, Brazil, to evaluate different intercroppings between cowpea (cv. Mauá) and corn (cv. AG-1051) under organic farming system. The experiment was carried out in an area of ultisol employing a randomized block design with four replicates. Treatments consisted of four intervals of cowpea sowing, as follows: (E1) 21 days prior to corn; (E2) 14 days prior to corn; (E3) 7 days prior to corn; and (E4) cowpea and corn sowed on the same day. Sole crops of cowpea and corn were included, both sown along with treatment E4. Intercropping with cowpea did not affect corn yield as immature (green) spikes and also had no influence in terms of the spikes basal diameter and length, regardless the intervals between sowing dates. As for cowpea, the sole crop productivity in green beans was superior to its intercropping with corn. The data obtained for the Area Equivalency Index (AEI), higher than 1.0 in all cases, indicated that intercrops were efficient in agronomic/biological terms. Considering, in addition, the yield of each component crop intercropping, cowpea sowing 21 days preceding corn was most adequate to the organic management adopted under regional conditions.

Keywords: Vigna unguiculata, Zea mays, Area Equivalency Index, agroecology.

(Recebido para publicação em 28 de janeiro de 2009; aceito em 6 de abril de 2010) (Received on January 28, 2009; accepted on April 6, 2010)

$\mathrm{A}$ cultura do caupi [Vigna unguiculata L. (Walp.)] vem crescendo de importância no estado do Rio de Janeiro, onde é exclusivamente praticada por pequenos agricultores de base familiar. Os principais municípios produtores são Cachoeiras de Macacú e Magé, na Região Litorânea, e São Francisco de Itabapoana, São João da Barra e Cardoso Moreira, localizados na Região Norte.

Os genótipos cultivados no Rio de Janeiro provêm de sementes introduzidas anos atrás junto a migrações de nordestinos e são localmente conhecidos como Mauá, Costelão, Piabetá e Feijãode-Corda. Geralmente, o caupi é semeado em sucessão a culturas tradicionais e mais exigentes, como as do quiabeiro e do milho, buscando aproveitar o efeito residual das adubações. É quase sempre comercializado na forma de vagens imaturas, sobretudo para consumo de grãos verdes em saladas ou refogados.

Constata-se baixa produtividade, em alguns casos, devido a diversos fatores, dentre os quais a incidência de pragas e doenças, misturas varietais e uso de semente própria, por vezes de qualidade duvidosa. Os cultivos consorciados são também freqüentes, predominantemente com o milho, para colheita de espigas verdes ou com o aipim-de-mesa, produtos de expressão destacada no mercado do Grande Rio (CEASA/RJ, 2007). As associações simultâneas entre culturas representam uma estratégia com potencial para aumento de produção por unidade de área cultivada, sendo, por isto, comumente adotadas na pequena agricultura (Bezerra Neto et al., 2001). Possibilitam, ainda, a otimização de insumos e mão-de-obra, além de contribuir no controle das populações de plantas daninhas nas lavouras (Taveira, 2000). Entretanto, a eficiência dessa prática agrícola depende essencialmente das espécies envolvidas, havendo necessidade de "companheirismo" entre elas para que o consórcio seja vantajoso em relação aos respectivos cultivos solteiros (Cecílio Filho \& Taveira, 2001; Oli- 
veira et al., 2005;). Fukay \& Trenbath (1993) já apontavam o desempenho promissor de consórcios entre plantas com distintos hábitos de crescimento e características morfológicas, gerando eficiência mútua na utilização de água e energia. Há evidências para melhoria da fertilidade do solo nos consórcios em que é incluído o caupi. Assim, Giller (2001) obteve produtividade superior do milho associado à leguminosa, especialmente quando esta foi semeada em alta densidade populacional.

$O$ consumo de produtos orgânicos no Rio de Janeiro passa por um processo de contínua expansão. Na rede de supermercados da grande metrópole já são com freqüência, encontrados hortifrutigranjeiros importados de outros estados, particularmente de São Paulo, que competem nesse setor ou segmento de comercialização. Todavia, quanto ao caupi e ao milho verde, os municípios produtores do estado do Rio são privilegiados, não somente pela proximidade geográfica, mas também - e sobretudo - porque reúnem condições climáticas que viabilizam semeaduras ao longo de todo o ano.

O objetivo deste estudo foi avaliar o desempenho agronômico de diferentes tipos de consórcio entre caupi e milho, em sistema orgânico de produção, com vistas à melhoria de renda e qualidade de vida no meio rural fluminense.

\section{MATERIAL E MÉTODOS}

O estudo foi desenvolvido durante o período de outono-inverno-primavera de 2007 no Sistema Integrado de Produção Agroecológica (SIPA, "Fazendinha Agroecologia km 47”), situado no município de Seropédica, Região Metropolitana do estado do Rio de Janeiro (Baixada Fluminense). Trata-se de um projeto de cooperação técnica entre a Embrapa Agrobiologia, a Universidade Federal Rural do Rio de Janeiro e a Pesagro-Rio (Estação Experimental de Seropédica), representando uma área de aproximadamente 70 ha destinada a pesquisas no âmbito da agricultura orgânica (Almeida et al., 2003). O solo da área experimental é classificado como um Argissolo Vermelho-Amarelo, cuja análise química, de acordo com a me- todologia descrita em Claessen (1997), forneceu os seguintes resultados: $\mathrm{pH}$

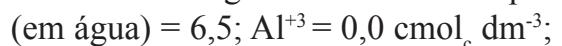
$\mathrm{Ca}^{+2}=3,0 \mathrm{cmol}_{\mathrm{c}} \mathrm{dm}^{-3} ; \mathrm{Mg}^{+2}=1,8 \mathrm{cmol}_{\mathrm{c}}$ $\mathrm{dm}^{-3} ; \mathrm{K}=420,0 \mathrm{mg} \mathrm{dm}^{-3} ; \mathrm{P}=57,9 \mathrm{mg}^{\mathrm{c}}$ $\mathrm{dm}^{-3} ; \mathrm{C}=1,52 \% ; \mathrm{MO}=2,62 \% ; \mathrm{N}=$ 0,101\%. Foi efetuada uma adubação pré-plantio do milho com esterco bovino, aplicando-se 1,0 L por metro linear de sulco de semeadura, o que correspondeu a $10 \mathrm{t} \mathrm{ha}^{-1}$. $\mathrm{O}$ caupi não foi diretamente adubado.

O preparo do solo foi mecanizado, realizando-se uma aração a $20 \mathrm{~cm}$ de profundidade, seguida de gradagem. Foram procedidas três capinas a enxada, em todas as parcelas, durante o ciclo das culturas. Empregou-se irrigação suplementar por aspersão, obedecendo a turno de rega único, independentemente do tratamento. Foram feitas três pulverizações com produto à base de óleo de neen (Azadiracta indica) para controle de coleópteros (Diabrotica speciosa e Cerotoma arcuata) e de pulgões (Aphis spp.) no caupi, e duas aplicações de formulação contendo BT (Bacillus thuringiensis) nas plantas de milho contra a lagarta do cartucho (Spodoptera frugiperda). A cultivar híbrida de milho AG-1051 e a cultivar Mauá de caupi foram utilizadas no estudo.

Os tratamentos constaram de quatro épocas ou intervalos de tempo de semeadura do caupi em relação à do milho, a saber: (E1) 21 dias antes do milho; (E2) 14 dias antes do milho; (E3) 7 dias antes do milho; e (E4) no mesmo dia do milho. Tratamentos correspondentes aos cultivos solteiro de milho (MM) e caupi (MC) foram incluídos, ambos semeados na data do tratamento E4. O delineamento experimental usado foi de blocos casualizados, com quatro repetições por tratamento.

O milho foi plantado em fileiras duplas espaçadas de 1,5 m, com 0,5 m entre cada linha componente. A densidade populacional do milho correspondeu a 40.000 plantas ha-1 (quatro plantas $\mathrm{m}^{-1}$ nas linhas). O caupi foi semeado no centro do espaço entre as fileiras duplas de milho. Mantiveram-se oito plantas $\mathrm{m}^{-1}$, estabelecendo-se, portanto, uma população também de 40.000 plantas ha ${ }^{-1}$.

As características avaliadas foram 1) no milho: diâmetro basal e comprimento da espiga verde desempalhada, colhida 89 dias após semeadura (DAS); produtividade (número e peso) em espigas verdes desempalhadas, colhidas aos 89 DAS; 2) no caupi: produtividade em vagens e grãos verdes (imaturos); número de grãos por vagem.

Os dados foram submetidos à análise de variância, sendo as médias comparadas pelo teste de Tukey ao nível de 5\% de probabilidade, através do Programa Sisvar, versão 4.3 (Ferreira, 2003). Para comparação entre consórcios e cultivos solteiros empregou-se o Índice de Equivalência de Área (IEA), que permite estimar a área necessária para que as produções em cultivo solteiro se igualem àquela obtida no cultivo consorciado (Moura, 1984). O IEA foi derivado da equação: $\mathrm{IEA}=\mathrm{C}_{\mathrm{A}} / \mathrm{M}_{\mathrm{A}}+\mathrm{C}_{\mathrm{B}} / \mathrm{M}_{\mathrm{B}}=$ $\mathrm{I}_{\mathrm{A}}+\mathrm{I}_{\mathrm{B}}$, onde $\mathrm{C}_{\mathrm{A}}=$ rendimento do caupi no consórcio; $\mathrm{M}_{\mathrm{A}}=$ rendimento do caupi em cultivo solteiro; $\mathrm{C}_{\mathrm{B}}=$ rendimento do milho no consórcio; $\mathrm{M}_{\mathrm{B}}=$ rendimento do milho em cultivo solteiro; $\mathrm{I}_{\mathrm{A}}=$ índice individual relativo ao caupi; e $\mathrm{I}_{\mathrm{B}}=$ índice individual relativo ao milho. $\mathrm{O}$ consórcio deve ser considerado eficiente quando o IEA ultrapassa o valor 1,0 (Soares et al., 2000).

\section{RESULTADOS E DISCUSSÃO}

O consórcio com o caupi não interferiu no desempenho do milho, com relação à produtividade em espigas verdes, independentemente do intervalo de tempo entre semeaduras.

Os valores referentes ao diâmetro basal e ao comprimento da espiga verde desempalhada não diferiram entre si pelo teste de Tukey a 5\% de probabilidade, tendo médias de 4,27 e 17,53, respectivamente. Esses resultados foram comparáveis àqueles encontrados por Devide (2006), ao estudar o cultivo orgânico consorciado do milho (cv. Eldorado) com o aipim-de-mesa (cv. IAC 576-70) na mesma localidade.

Soares et al. (2000), trabalhando com o milho 'AG-1051', assinalaram valores muito mais elevados para comprimento da espiga verde, alcançando médias de $32 \mathrm{~cm}$ no consórcio com o feijoeiro comum (Phaseolus vulgaris). No entanto, estes últimos autores utilizaram manejo convencional das 
Tabela 1. Produtividade do milho ('AG-1051') em cultivo solteiro e em diferentes tipos de consórcio com caupi ('Mauá'), sob manejo orgânico (yield of corn ('AG-1051') in different types of monocropping and intercropping with cowpea ('Mauá') under organic management). Seropédica, Embrapa Agrobiologoa, 2007.

\begin{tabular}{lcc}
\hline \multirow{2}{*}{ Tratamentos } & \multicolumn{2}{c}{ Espiga verde de milho } \\
\cline { 2 - 3 } & Peso total $\left(\mathbf{t ~ h a}^{-\mathbf{1}}\right)$ & $\mathbf{N}^{\mathbf{0}}$ espigas ha $^{-1}$ \\
\hline Consórcio E1 ${ }^{*}$ & $5,79^{\mathrm{ns}}$ & $40.000^{\mathrm{ns}}$ \\
Consórcio E2 & 5,79 & 41.250 \\
Consórcio E3 & 6,08 & 40.625 \\
Consórcio E4 & 5,78 & 38.750 \\
Cultivo solteiro (CS) & 5,96 & 39.375 \\
\hline CV $(\%)$ & 5,72 & 6,22 \\
\hline
\end{tabular}

*Consórcios: intervalos de tempo de semeadura do feijão-caupi antecedendo à do milho: E1 = 21 dias; E2 = 14 dias; E3 = 7 dias; E4 = no mesmo dia; ${ }^{\text {ns } O s ~ v a l o r e s ~(m e ́ d i a s ~ d e ~} 4$ repetições), nas colunas, não diferem entre si pelo teste de Tukey ao nível de 5\% de probabilidade.

Tabela 2. Produtividade do caupi ('Mauá') em cultivo solteiro e de diferentes tipos de consórcio com o milho ('AG-1051'), sob manejo orgânico (yield of cowpea ('Mauá') in different types of monocropping and intercropping with corn ('AG-1051') under organic management). Seropédica, Embrapa Agrobiologoa, 2007.

\begin{tabular}{lcc}
\hline \multirow{2}{*}{ Tratamentos } & \multicolumn{2}{c}{ Produtividade $\left(\mathbf{k g ~ h a}^{\mathbf{1}}\right)$} \\
\cline { 2 - 3 } & Vagens verdes & Grãos verdes $^{*}$ \\
\hline Consórcio E1* & $1.440,08 \mathrm{~b} * *$ & $978,75 \mathrm{~b}$ \\
Consórcio E2 & $670,93 \mathrm{c}$ & $430,75 \mathrm{c}$ \\
Consórcio E3 & $382,22 \mathrm{c}$ & $295,25 \mathrm{c}$ \\
Consórcio E4 & $600,89 \mathrm{c}$ & $424,00 \mathrm{c}$ \\
Cultivo solteiro (CS) & $1.900,59 \mathrm{a}$ & $1405,75 \mathrm{a}$ \\
\hline CV (\%) & 25,50 & 24,55 \\
\hline
\end{tabular}

*Consórcios: intervalos de tempo de semeadura do caupi antecedendo à do milho: E1 = 21 dias; E2 = 14 dias; E3 = 7 dias; E4 = no mesmo dia; **Os valores (médias de 4 repetições), nas colunas, seguidas de letras iguais não diferem entre si pelo teste de Tukey ao nível de $5 \%$ de probabilidade.

Tabela 3. Índices de Equivalência de Área (IEA) relativos a diferentes tipos de consórcio de caupi ('Mauá') e milho ('AG-1051'), sob manejo orgânico (Area Equivalency Índex (AEI) in different types of intercropping cowpea ('Mauá) and corn ('AG-1051) under organic management). Seropédica, Embrapa Agrobiologoa, 2007.

\begin{tabular}{lcccccc}
\hline \multirow{2}{*}{ Tratamentos } & \multicolumn{2}{c}{ Caupi } & & \multicolumn{2}{c}{ Milho } & \multirow{2}{*}{ IEA } \\
\cline { 2 - 3 } & PGV** $^{*}$ & $\mathbf{I}_{\mathbf{A}}$ & & PED $^{* * *}$ & $\mathbf{I}_{\mathbf{B}}$ & \\
\hline Consórcio E1* & 978,75 & 0,70 & & 5,79 & 0,97 & 1,67 \\
Consórcio E2 & 430,75 & 0,31 & & 5,79 & 0,97 & 1,28 \\
Consórcio E3 & 295,25 & 0,21 & & 6,08 & 1,01 & 1,22 \\
Consórcio E4 & 424,00 & 0,30 & & 5,78 & 0,97 & 1,27 \\
\hline
\end{tabular}

*Consórcios: intervalos de tempo de semeadura do caupi antecedendo à do milho: E1 = 21 dias; E2 = 14 dias; E3 = 7 dias; E4 no mesmo dia; **produtividade em grãos verdes (kg $\left.\mathrm{ha}^{-1}\right) ; * *$ produtividade em espigas verdes desempalhadas $\left(\mathrm{t} \mathrm{ha}^{-1}\right)$.

culturas, com o emprego de adubação mineral, pesticidas sintéticos, etc, o que justificaria as diferenças em relação ao presente estudo, quanto ao comprimento da espiga verde.

$\mathrm{O}$ rendimento em peso total de espigas verdes desempalhadas (Tabela 1), foram estatisticamente significativas. Esses resultados indicaram, portanto, que os sistemas de consórcio, nas condições estudadas, não oferecem risco de perda na produtividade do milho.

Com referência ao caupi, em contrapartida, houve efeito significativo dos tratamentos para todos os componentes de produção, com exceção do número de grãos por vagem (Tabela 2). Quanto à colheita de vagens verdes, no consórcio em que o caupi foi semeado 21 dias antes do milho (E1) e no cultivo solteiro da leguminosa (MC), a produtividade foi superior à dos demais tratamentos. Durante o experimento, observou-se que nas parcelas correspondentes ao tratamento E1 praticamente não ocorria competição por luz até a fase de florescimento do caupi, que teve lugar ao redor dos 50 dias a contar do respectivo plantio, o que deve ter influenciado positivamente seu desempenho produtivo.

Já com relação à produtividade em grãos verdes, o cultivo solteiro do caupi superou qualquer dos consórcios com o milho (Tabela 2). Os tratamentos E2, E3 e E4 não diferiram entre si. Já o tratamento E1 foi superior aos outros consórcios, porém, não alcançou o nível de produtividade do cultivo solteiro.

O número médio de grãos por vagem de caupi variou de 14,10 no tratamento E1 a 13,24 no cultivo solteiro. Tais diferenças, contudo, não foram estatisticamente significativas, evidenciando que os consórcios com o milho não afetaram esse importante componente do rendimento agronômico da leguminosa. Souza et al. (2004) também não encontraram diferenças significativas quando compararam consórcios com o milho, variando a densidade populacional do caupi, sendo a média geral reportada, de 14,2 grãos por vagem, comparável à do presente estudo.

$\mathrm{Na}$ Tabela 3, constam os valores relativos aos Índices de Equivalência de Área (IEA), todos superiores a 1,0, assim indicando que os sistemas de consórcio entre as culturas de caupi e milho foram eficientes. Isto significa que os cultivos solteiros exigiriam até $67 \%$ a mais em termos de área plantada para igualar a produção obtida com o cultivo consorciado. Rusinamhodzi et al. (2006) registraram IEAs acima da unidade ao 
estudarem o consórcio do caupi com o algodoeiro, sinalizando, de forma análoga, para a conveniência do sistema. Entretanto, tão somente o IEA, ainda que positivo, não deve ser considerado suficiente para uma tomada de decisão, devendo-se levar em conta as produtividades de cada cultura componente do consórcio (Moura, 1984). Nesse sentido, a semeadura do caupi antecipada de 21 dias em relação à do milho (tratamento E1) afigurou-se como a mais adequada ao manejo orgânico descrito e às condições edafoclimáticas da Baixada Fluminense. Assim, o tratamento E1 não apenas proporcionou máximo IEA, mas também correspondeu à modalidade de consórcio em que o índice $\left(\mathrm{I}_{\mathrm{A}}\right)$ referente ao caupi foi o maior, sem prejuízo para o índice individual $\left(\mathrm{I}_{\mathrm{B}}\right)$ do milho (Tabela 3).

Nos consórcios avaliados, a produtividade do milho ('AG-1051') em espigas verdes equivale à de seu cultivo solteiro. Já o rendimento do caupi ('Mauá') em grãos verdes sofre interferência do milho, sendo inferior no cultivo consorciado em comparação ao cultivo solteiro.

Não obstante, pode-se observar pelos índices de Equivalência de Área (IEAs) obtidos, viabilidade da consorciação entre as duas culturas, no sistema orgânico de produção e arranjos espaciais adotados.

Ainda com base nos valores dos componentes dos IEAs, a semeadura do caupi antecedendo em três semanas (21 dias) a do milho, é a mais indicada para plantios irrigados de outono em regiões de baixa altitude do estado do Rio de Janeiro, cujo clima seja semelhante ao da Baixada Fluminense.

\section{AGRADECIMENTOS}

Os autores agradecem à agência de fomento à pesquisa CAPES, pela concessão de auxílio-bolsa.

\section{REFERÊNCIAS}

ALMEIDA DL; GUERRA JGM; RIBEIRO RLD. 2003. Sistema Integrado de Produção Agroecológica: uma experiência de pesquisa em agricultura orgânica. Seropédica: Embrapa Agrobiologia, 37 p. (EMBRAPA CNPAB, Documentos, 169).

BEZERRA NETO F; ANDRADE FV; SANTOS JÚNIOR JJ; NEGREIROS MZ. 2001. Desempenho da cenoura em cultivo solteiro e consorciado com quatro cultivares de alface em dois sistemas de cultivo em faixas. Horticultura Brasileira 19: 2, Suplemento (CD-ROM).

CEASA/RJ - Centrais de Abastecimento do Estado do Rio de Janeiro. 2007. Disponível em www.ceasa.rj.gov.br/ceasa/consultas/htm.

CECÍLIO FILHO AB; TAVEIRO MCGS. 2001. Produtividade da cultura de beterraba em função da época de estabelecimento do consórcio com rúcula. Horticultura Brasileira 19: 2, Suplemento (CD-ROM).

CLAESSEN MEC. 1997. Manual de métodos de análise de solo. 2 ed., Rio de Janeiro: Embrapa Solos, 212 p. (EMBRAPA CNPS. Documentos, 1).

DEVIDE ACP. 2006. Sistema orgânico de produção de mandioca consorciada com milho e caupi. Seropédica: UFRRJ. 85p (tese mestrado).

FERREIRA DF. 1999. SISVAR. Versão 4.3: Suporte econômico. Brasília: CAPES, CNPq; Lavras: Universidade Federal de Lavras.

FUKAI S; TRENBATH BR. 1993. Processes determining intercrop productivity and yields of component crops. Field Crops Research 34: $239-245$.

GILLER KE. 2001. Nitrogen fixation in tropical cropping systems. 2 ed. Wallingford: CAB International, 448p.

MOURA PAM. 1984. Alguns indicadores para analise econômica do consórcio feijão e milho. Informe Agropecuário 10: 3-10.

OLIVEIRA FL; RIBAS RGT; JUNQUEIRA RM; PADOVAN MP; GUERRA JGM; ALMEIDA DL; RIBEIRO RLD. 2005. Desempenho do consórcio entre repolho e rabanete com précultivo de crotalária, sob manejo orgânico. Horticultura Brasileira 23: 184-188.

RUSINAMHODZI L; MURWIRA HK; NYAMANGARA J. 2006. Cotton-cowpea intercropping and its $\mathrm{N}_{2}$ fixation capacity improves yield of a subsequent maize crop under Zimbabwean rain-fed conditions. Plant and Soil 287:327-336.

SOARES DM; DEL PELOSO MJ; KLUTHCOUSKI J; GANDOLFI LC; FARIA DJ. 2000. Tecnologia para o sistema consórcio de milho verde com feijão no plantio de inverno. Santo Antônio de Goiás: Embrapa Arroz e Feijão, 51p. (EMBRAPA CNPAF. Boletim de Pesquisa, 10).

SOUZA MLO; TÁVORAS FJF; BLEICHER E; PITOMBEIRA JB. 2004. Efeito do consórcio do milho Zea mays L. com o feijão-de-corda Vigna unguiculata $\mathrm{L}$. Walp. no rendimento de grãos, uso eficiente da terra e ocorrência de pragas. Revista Ciência Agronômica 35: 196-205.

TAVEIRA MCGS. 2000. Produtividade da cultura da beterraba em função da consorciação com rúcula em diferentes épocas de semeadura. Jaboticabal: UNESP/FCAV, 29 p. (Monografia graduação). 